\title{
p53-Independent ceramide formation in human glioma cells during $\gamma$-radiation-induced apoptosis
}

\author{
S Hara ${ }^{*, 1}$, S Nakashima ${ }^{2}$, T Kiyono ${ }^{3}$, M Sawada ${ }^{1}$, S Yoshimura ${ }^{1}$, \\ T Iwama ${ }^{1}$, Y Banno ${ }^{2}$, J Shinoda ${ }^{1}$ and N Sakai ${ }^{1}$ \\ 1 Department of Neurosurgery, Gifu University School of Medicine, \\ Tsukasamachi-40, Gifu 500-8705, Japan; \\ 2 Department of Cell Signaling, Division of Cellular and Molecular Biology, \\ Gifu University School of Medicine, Tsukasamachi-40, Gifu 500-8705, Japan; \\ ${ }^{3}$ Virology Division, National Cancer Center Research Institute, 5-1-1 Tsukiji, \\ Chuohku, Tokyo 104-0045, Japan \\ * Corresponding author: S Hara, Department of Neurosurgery, Gifu University \\ School of Medicine, Tsukasamachi-40, Gifu 500-8705, Japan. \\ Tel: + 81-58-267-2348; Fax: + 81-58-265-9025; \\ E-mail: $22105013 @$ guedu.cc.gifu-u.ac.jp
}

Received 22.7.03; revised 15.1.04; accepted 10.2.04; published online 16.4.04 Edited by D Altieri

\section{Abstract}

Although the p53 tumor-suppressor gene product plays a critical role in apoptotic cell death induced by DNA-damaging chemotherapeutic agents, human glioma cells with functional p53 were more resistant to $\gamma$-radiation than those with mutant p53. U-87 MG cells with wild-type p53 were resistant to $\gamma$-radiation. U87-W E6 cells that lost functional p53, by the expression of type 16 human papillomavirus E6 oncoprotein, became susceptible to radiation-induced apoptosis. The formation of ceramide by acid sphingomyelinase (A-SMase), but not by neutral sphingomyelinase, was associated with $\mathrm{p53}$ independent apoptosis. SR33557 (2-isopropyl-1-(4-[3-Nmethyl- $N$-(3,4-dimethoxybphenethyl)amino]propyloxy)benzene-sulfonyl) indolizine, an inhibitor of A-SMase, suppressed radiation-induced apoptotic cell death. In contrast, radiationinduced A-SMase activation was blocked in glioma cells with endogenous functional p53. The expression of acid ceramidase was induced by $\gamma$-radiation, and was more evident in cells with functional p53. $\mathrm{N}$-oleoylethanolamine, which is known to inhibit ceramidase activity, unexpectedly downregulated acid ceramidase and accelerated radiation-induced apoptosis in U87-W E6 cells. Moreover, cells with functional p53 could be sensitized to $\gamma$-radiation by $N$-oleoylethanolamine, which suppressed radiation-induced acid ceramidase expression and then enhanced ceramide formation. Sensitization to $\gamma$ radiation was also observed in U87-MG cells depleted of functional p53 by retroviral expression of small interfering RNA. These results indicate that ceramide may function as a mediator of $\mathrm{p} 53$-independent apoptosis in human glioma cells in response to $\gamma$-radiation, and suggest that p53-dependent expression of acid ceramidase and blockage of A-SMase activation play pivotal roles in protection from $\gamma$-radiation of cells with endogenous functional $p 53$.

Cell Death and Differentiation (2004) 11, 853-861.

doi:10.1038/sj.cdd.4401428

Published online 16 April 2004
Keywords: apoptosis; p53; glioma; radiation; ceramide

Abbreviations: $\mathrm{N}$ - and A-SMase, neutral- and acid- sphingomyelinase; SM, sphingomyelin; HPV-16, type 16 human papillomavirus; GADD45, growth arrest and DNA-damage-inducible gene 45; OE, $\mathrm{N}$-(cis-9-octadecenoyl)ethanol-amine ( $\mathrm{N}$-oleoylethanolamine); SR33557, (2-isopropyl-1-(4-[3- $N$-methyl- $N$-(3, 4-dimethoxybphenethyl)amino]propyloxy)benzene-sulfonyl) indolizine; TNF, tumor necrosis factor; SPP, sphingosine-1-phosphate; DMEM, Dulbecco's modified Eagle's medium; FBS, fetal bovine serum; PBS, phosphate-buffered saline; MTT, 3-(4,5dimethyl-2-thiazolyl)-2, 5-diphenyl-2H-tetrazolium bromide (methylthiazoletetrazolium); siRNA, small interfering RNA; shRNA, short hairpin RNA; HPTLC, high-performance thin-layer chromatography; SDS-PAGE, sodium dodecylsulfate polyacrylamide gel electrophoresis

\section{Introduction}

Malignant gliomas, the most common malignant brain tumors, are usually incurable. While radiation therapy is the most effective postoperative adjuvant treatment, it does not substantially alter long-term outcomes ${ }^{1}$ due to the characteristic in vivo and in vitro radioresistance of these tumors. ${ }^{2}$ The underlying molecular mechanism(s) of their radioresistance and the radiation-induced apoptotic death of glioma cells remain poorly understood. DNA-damaging agents, used to treat malignant tumors, induce tumor cell apoptosis. ${ }^{3}$ Caspases, a family of cysteine proteases, play a central role in the apoptotic cascade. ${ }^{4}$ Ceramide, a product of the sphingomyelinase (SMase)-catalyzed hydrolysis of sphingomyelin (SM), is closely implicated in the apoptosis of several types of cells. ${ }^{5}$ We previously reported the molecular mechanism by which etoposide, an anticancer drug, induces ceramide generation in human glioma cells. ${ }^{6-8}$ However, the role of ceramide in radiation-induced apoptosis in gliomas remains to be clarified.

Chemotherapeutic agents upregulate and activate p53, a tumor-suppressor gene product. p53 protein is a prerequisite for cell-cycle arrest in the repair of damaged DNA, or alternatively, for the promotion of apoptosis, when DNA damage is too extreme. ${ }^{9}$ p53 stimulates transcriptional activation to regulate as many as $200-400$ gene products involved in cell-cycle control (p21 ${ }^{\mathrm{WAF} 1}$ ), DNA repair and synthesis (GADD45, growth-arrest and DNA-damage-inducible gene 45), and apoptosis (Bax and Apaf-1). ${ }^{10,11}$ Cells with functional p53 or exogenously expressed p53 are usually more sensitive to chemotherapeutic agents such as etoposide than are cells with mutant p53. ${ }^{8,12,13}$ Supraphysiological levels of $\mathrm{p} 53$, such as those generated by adenovirus delivery, trigger apoptosis in glioma cell lines containing the mutant $\mathrm{p} 53,{ }^{14}$ and enhance the radiosensitivity of glioma cells with wild-type p53. ${ }^{15-17}$ However, the role of endogenous p53 in radiation-induced apoptosis of glioma cells remains to be elucidated. Glioma cells with p53 mutations are reportedly 
more sensitive to $\gamma$-radiation than those with endogenous wildtype (functional) p53. ${ }^{18,19}$ Endogenous functional p53 mediates radiation-induced $\mathrm{G}_{1}$ arrest rather than apoptosis. ${ }^{18}$ These results point to p53-independent apoptosis of glioma cells with p53 mutations, although the apoptotic signaling pathway(s) remains understood. However, Badie et al. ${ }^{16}$ reported that radiation did not induce significant apoptosis in glioma cells regardless of their p53 status.

In the present study, we evaluated the involvement of endogenous p53 in the radiation sensitivity of glioma cells, and examined the pathway(s) of p53-independent apoptosis. Functional p53 was inactivated with the E6 protein of human papillomavirus type 16 (HPV-16). ${ }^{20}$ We found that gliomas with endogenous functional p53 were relatively resistant to $\gamma$ radiation and that the loss of functional p53 rendered them susceptible to $\gamma$-radiation-induced apoptosis. We confirmed our results in glioma cells depleted of p53 by a small interfering RNA (siRNA) technique, ${ }^{21}$ which uses retroviral expression of short hairpin RNA (shRNA). In the p53independent apoptotic pathway, ceramide, produced by acid SMase (A-SMase), appeared to function as a mediator. Furthermore, upregulation of acid ceramidase and blockage of A-SMase activation, which synergistically inhibit the formation of ceramide, may play an important role in the radioresistance of glioma cells with endogenous functional p53.

\section{Results}

\section{Sensitivity to $\gamma$-radiation based on the p53 status of human glioma cells}

We first examined the cytotoxic effects of $\gamma$-radiation on two human glioma cell lines of different p53 status. U-373 MG cells with mutant (nonfunctional) p53 were more sensitive to $\gamma$ radiation than U-87 MG cells with wild-type (functional) p53 (Figure 1a). Under a phase-contrast microscopy, U-373 MG cells did, while U-87 MG cells did not, manifest marked morphological changes at $72 \mathrm{~h}$ after $25 \mathrm{~Gy}$ irradiation.

To confirm the role of endogenous p53 in the radiosensitivity of human glioma cells, functional p53 was inactivated by the expression of HPV-16 E6 oncoprotein, which binds p53 and accelerates its proteolytic degradation via the ubiquitin pathway. ${ }^{20}$ Using a retroviral vector, wild-type or mutant E6 proteins ${ }^{22}$ and an empty vector were expressed in U-87 MG cells (designated U87-W E6, U87-M E6, and U87LXSN, respectively). ${ }^{8} \gamma$-Radiation induced the accumulation of p53 protein at $6 \mathrm{~h}$ after $\gamma$-radiation, thereafter the accumulated p53 was gradually degraded in U87-LXSN and U87-M E6 cells. In contrast, $\gamma$-radiation-induced p53 expression was abolished in U87-W E6 cells with wild-type E6 protein (Figure 2a). The accumulation of p53-inducible proteins, ${ }^{10}$ p2 $1^{\text {WAF1 }}$ and GADD45, was almost completely suppressed in U87-W E6 cells (Figure 2b); thus, p53 was virtually inactivated by E6 protein in these cells.

Exposure to $\gamma$-radiation induced time- and dose-dependent increases in apoptosis (Figure 1). U87-W E6 cells were more sensitive to $\gamma$-radiation than U87-LXSN and U87-M E6 cells; the latter were almost completely resistant to $\gamma$-radiation. Nuclear staining of U87-W E6 cells with Hoechst 33258
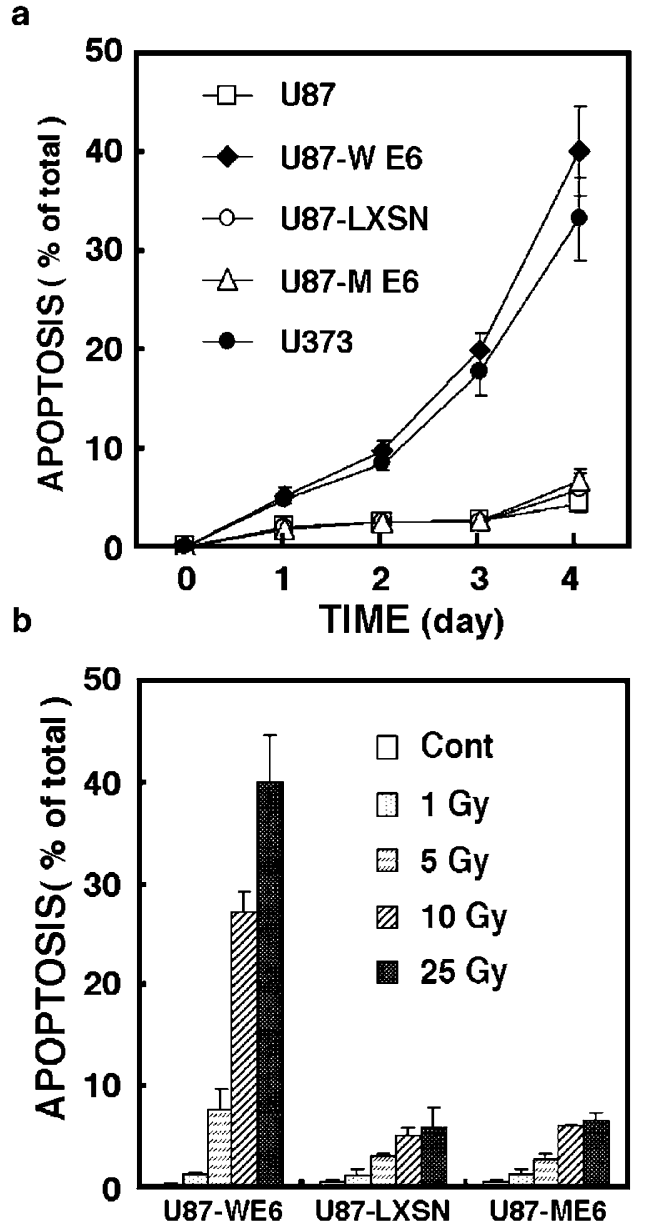

Figure 1 Radiation-induced apoptosis of human glioma cells with different p53 status. (a) U-87 MG, U87-LXSN, U87-W E6, U87-M E6, and U-373 MG cells were irradiated at $25 \mathrm{~Gy}$, and cultured for the indicated periods. (b) U87-LXSN, U87-W E6, and U87-M E6 cells were exposed to the indicated doses of $\gamma$ radiation and incubated for 4 days. The cells with fragmented and condensed nuclei were counted in over 1000 cells under a fluorescent microscope. Data are means \pm S.D. from three independent experiments, each performed in triplicate

a

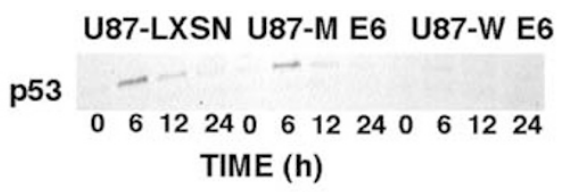

b U87-LXSN U87-M E6 U87-W E6

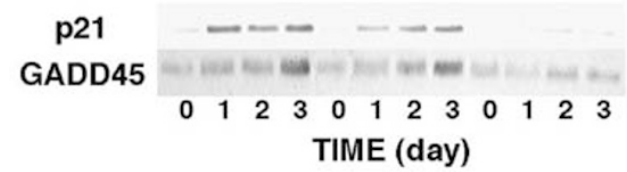

Figure 2 Radiation-induced accumulation of (a) p53 and (b) p53-dependent proteins, p21 WAF1, and GADD45. U87-LXSN, U87-M E6, and U87-W E6 cells were irradiated at $25 \mathrm{~Gy}$, and incubated for the indicated periods. Cellular proteins were subjected to SDS-PAGE and immunoblotted with antibodies against p53, p21 ${ }^{\mathrm{WAF} 1}$, or GADD45. Results are representative of three separate experiments with compatible outcomes 
revealed typical apoptotic changes such as condensation and fragmentation of the nuclei (data not shown). Apoptotic cell death was also confirmed by the activation of caspases-3 and -9. U87-LXSN and U87-M E6 cells manifested hardly any typical apoptotic changes or activation of caspases (data not shown).

Differences in the radiosensitivity of glioma cells with and without endogenous functional p53 were assessed with a clonogenic assay for survival (Figure 3). The clonogenic survival of U87-W E6 cells was significantly lower than that of U87-LXSN and U87-M E6 cells, which possess $\mathrm{p} 53$, indicating that functional p53 confers resistance to $\gamma$-radiation-induced apoptosis. Our observations are consistent with those of Haas-Kogan et al., ${ }^{18}$ who proposed that endogenous functional p53 mediates the radiation-induced $\mathrm{G}_{1}$ arrest of glioma cells rather than apoptosis.

\section{Formation of ceramide via activation of A-SMase in the course of $\gamma$-radiation-induced glioma cell death}

Intracellular ceramide levels following $\gamma$-radiation were measured by enzymatic analysis using Escherichia coli diacylglycerol kinase and by metabolic labeling of cells with $\left[{ }^{14}\right.$ C]palmitic acid. ${ }^{6,8}$ The ceramide level in U87-W E6 cells increased on day 2 and peaked at three times the control level on day 3 (Figure $4 \mathrm{a}$ ). A similar $\left[{ }^{14} \mathrm{C}\right]$ ceramide formation profile was obtained for cells labeled with $\left[{ }^{14} \mathrm{C}\right]$ palmitic acid (data not shown). The ceramide levels of $\gamma$-irradiated U87-LXSN cells were above the nonirradiated controls (Figure $4 \mathrm{~b}$ ), but the increase was not statistically significant. $\gamma$-Radiation gave rise to an increase in A-SMase- but not N-SMase activity on day 1 ; this activity peaked on day 3 in U87-W E6 cells. No significant changes in A-SMase activity were noted in U87LXSN and U87-M E6 cells (Figure 5). These results suggest that functional p53 negatively regulates A-SMase activation

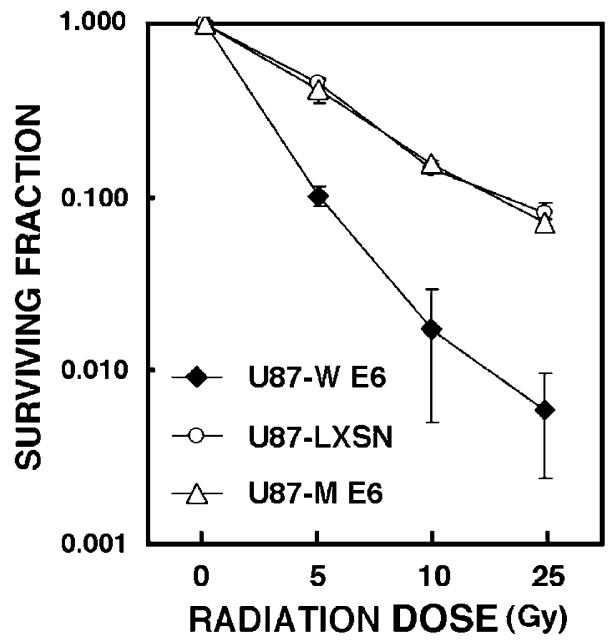

Figure 3 Clonogenic survival after $\gamma$-radiation. U87-LXSN, U87-M E6, and U87-W E6, cells were $\gamma$-irradiated at the indicated doses, and cultured for 3 days. The cells were then trypsinized, and replated into $100-\mathrm{mm}$ dishes. After incubation for 2 weeks, dishes were stained with trypan blue and colonies with over 50 cells were counted. Data are means + S.D. from three independent experiments, each performed in triplicate a

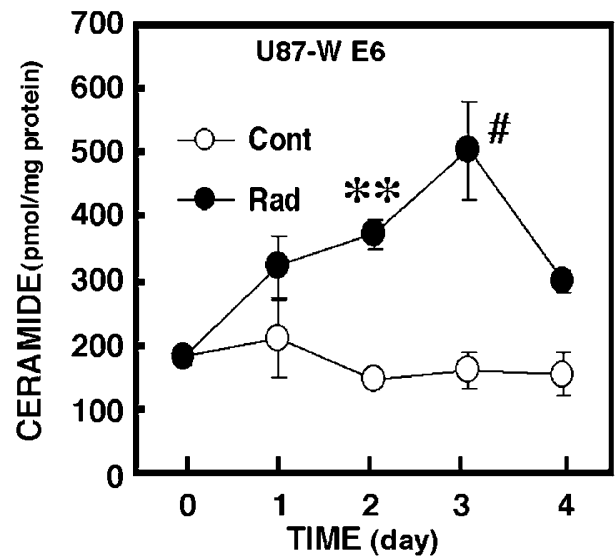

b

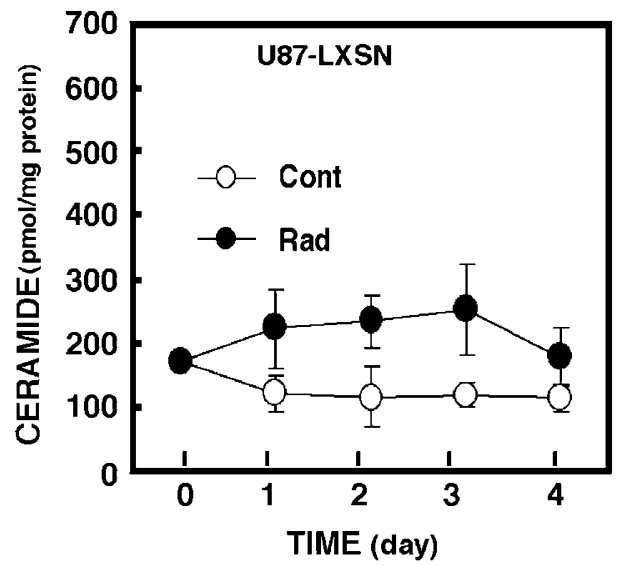

Figure 4 Radiation-induced ceramide formation in (a) U87-W E6 and (b) U87LXSN cells. The cells were irradiated at $25 \mathrm{~Gy}$ (Rad), and cultured for the indicated periods. Ceramide content was measured by the $E$. coli diacylglycerol kinase assay. Data are means \pm S.D. from three independent experiments, each performed in triplicate. ${ }^{* \star} P<0.05,{ }^{\#} P<0.1$ versus nonirradiated control (Cont): two-way ANOVA followed by Scheffe's post hoc test

triggered by $\gamma$-radiation. To further examine the role of A-SMase in $\gamma$-radiation-induced apoptosis, we used SR33557 (2-isopropyl-1-(4-[3- $N$-methyl- $N$-(3,4-dimethoxybphenethyl)amino]propyloxy)benzene-sulfonyl) indolizine, a potent inhibitor of A-SMase activation by various stimuli. ${ }^{23,24}$ As shown in Table 1, SR33557 prevented $\gamma$-radiation-induced activation of A-SMase in U87-W E6 cells below the control level, but had no effect on N-SMase activity. In fact, it suppressed $\left[{ }^{14} \mathrm{C}\right]$ ceramide formation in $\left[{ }^{14} \mathrm{C}\right]$ palmitic acidlabeled U87-W E6 cells (Figure 6a). The number of apoptotic U87-W E6 cells with typical apoptotic features such as condensation and fragmentation of nuclei was suppressed by SR33557 (Figure 6b). Our finding that SR33557 inhibits apoptosis was supported by 3-(4,5-Dimethyl-2thiazolyl)-2,5-diphenyl-2H-tetrazolium bromide (methylthiazoletetrazolium; MTT) assay results that showed an increase in viable cells.

\section{Change in acid ceramidase}

Overexpression of acid ceramidase protects cells from tumor necrosis factor- $\alpha$ (TNF- $\alpha$ )-induced cell death. ${ }^{25}$ We found that 


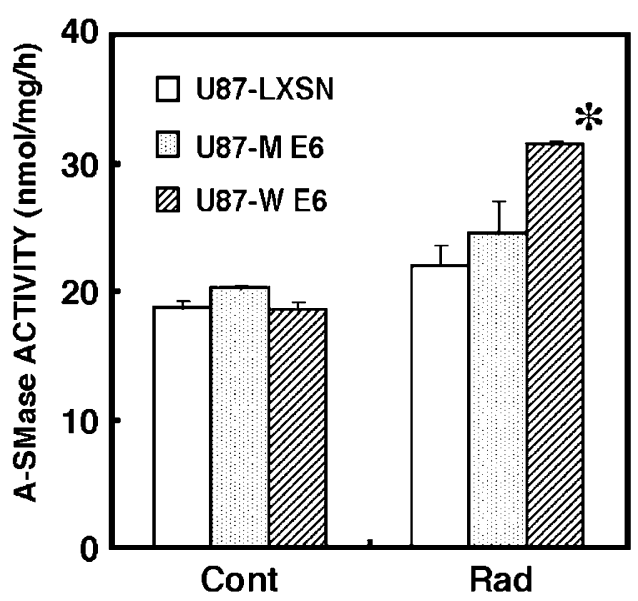

Figure 5 Changes of A-SMase activity in U87-LXSN, U87-W E6, and U87-M E6 cells exposed to $\gamma$-radiation. The cells were treated with (Rad) or without (Cont) 25 Gy $\gamma$-radiation and cultured for 3 days. The activity of A-SMase was determined using a mixed micelle assay system with [methyl- $\left.{ }^{14} \mathrm{C}\right] \mathrm{SM}$ at pH 5.5. Data are means + S.D. from three independent experiments, each performed in triplicate. ${ }^{* *} P<0.05$ versus nonirradiated control: two-way ANOVA followed by Scheffe's post hoc test

Table 1 Effects of SR33557 on SMase activation induced by $\gamma$-radiation

\begin{tabular}{lccc}
\hline $\begin{array}{l}\text { Time } \\
\text { (days) }\end{array}$ & $\begin{array}{c}\text { SR33557 } \\
(\mu \mathrm{M})\end{array}$ & $\begin{array}{c}\text { A-SMase } \\
(\mathbf{n m o l} / \mathbf{m g} / \mathbf{h})\end{array}$ & $\begin{array}{c}\text { N-SMase } \\
(\mathbf{n m o l} / \mathbf{m g} / \mathbf{h})\end{array}$ \\
\hline & 0 & $27.5 \pm 0.5$ & $1.9 \pm 0.5$ \\
2 & 5 & $4.4 \pm 0.1^{*}$ & $1.6 \pm 0.5$ \\
& 10 & $3.8 \pm 0.3^{*}$ & $1.2 \pm 0.3$ \\
3 & 0 & $35.8 \pm 5.0$ & $1.8 \pm 0.2$ \\
& 5 & $8.7 \pm 0.4^{*}$ & $1.6 \pm 0.0$ \\
& 10 & $1.8 \pm 2.2^{*}$ & $1.4 \pm 0.2$ \\
\hline
\end{tabular}

U87-W E6 cells were preincubated with 5 or $10 \mu \mathrm{M} \mathrm{SR} 33557$ for $6 \mathrm{~h}$, and then exposed to $25 \mathrm{~Gy} \gamma$-radiation. The activities of $\mathrm{N}$-SMase and A-SMase were determined 2 or 3 days after $\gamma$-radiation using a mixed micelle assay system with [methyl- ${ }^{14} \mathrm{C}$ ]SM at pH 7.5 and 5.5, respectively. Data are means \pm S.D. from two independent experiments, each performed in triplicate. ${ }^{*} P<0.01$ versus $\gamma$ radiation alone: two-way ANOVA followed by Scheffe's post hoc test.

acid ceramidase, which metabolizes ceramide to sphingosine, was upregulated by $\gamma$-radiation in both U87-LXSN and U87-W E6 cells (Figure 7). In U87-LXSN cells, acid ceramidase peaked at more than three times the control level and elevation persisted until day 4. In U87-W E6 cells, acid ceramidase was transiently increased, peaked on day 2 , and returned to the control level on day 4 . These results suggest that acid ceramidase expression may be partly regulated by $\mathrm{p} 53$.

To better understand the role of acid ceramidase, a ceramide-degrading enzyme, in radiation-induced apoptosis, we used $\mathrm{N}$-oleoylethanolamine (OE), a ceramidase inhibitor that potentiates stimulus-induced ceramide accumulation. ${ }^{6,25,26}$ At $25 \mu \mathrm{M}$, OE not only augmented ceramide accumulation but also, surprisingly, downregulated the enhanced expression of acid ceramidase triggered by $\gamma$ radiation (Figure 8). As expected, OE accelerated radiationinduced $\left[{ }^{14} \mathrm{C}\right]$ ceramide formation in $\left[{ }^{14} \mathrm{C}\right]$ palmitic acid-labeled U87-W E6 cells, leading to an increase in the number of apoptotic cells. On day 3 , the $\left[{ }^{14} \mathrm{C}\right]$ ceramide level as well as

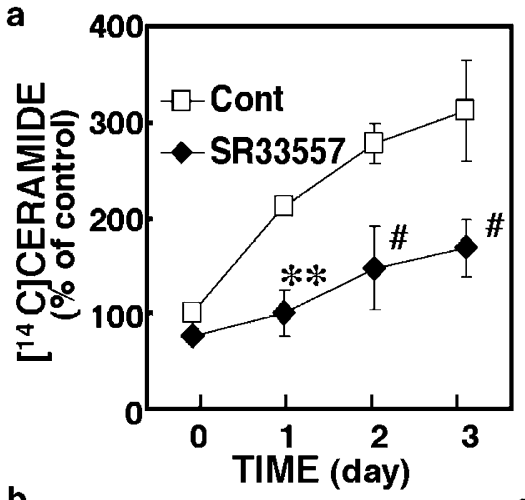

b

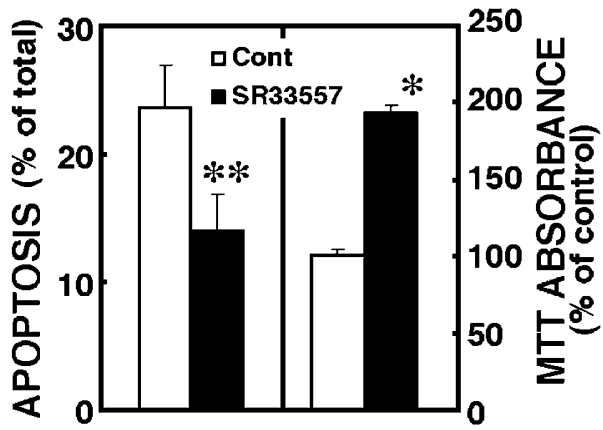

Figure 6 Effects of SR33557 on radiation-induced (a) ceramide formation and (b) apoptosis. U87-W E6 cells were preincubated with $5 \mu \mathrm{M} \mathrm{SR} 33557$ for $6 \mathrm{~h}$, and then were irradiated at $25 \mathrm{~Gy}$. (a) Changes of $\left[{ }^{14} \mathrm{C}\right]$ ceramide in $\left[{ }^{14} \mathrm{C}\right]$ palmitic acidlabeled cells were determined at the indicated periods after $\gamma$-radiation. The radioactivity in $\left[{ }^{14} \mathrm{C}\right]$ ceramide in unstimulated control (time 0 ) was designated as $100 \%$. (b) The cells with fragmented and condensed nuclei, stained with Hoechst 33258, were counted in over 1000 cells under a fluorescent microscope 3 days after $\gamma$-radiation. The MTT absorbance of each sample was measured using a microplate reader 3 days after $\gamma$-radiation and shown as \% of control. Data are means \pm S.D. from three independent experiments, each performed in triplicate. ${ }^{\star} P<0.01,{ }^{* *} P<0.05,{ }^{\#} P<0.1$ versus $\gamma$-radiation alone: two-way ANOVA followed by Scheffe's post hoc test

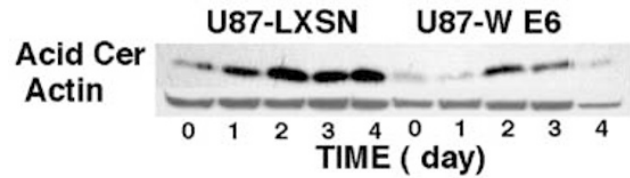

Figure 7 Radiation-induced changes of the protein level of acid ceramidase (Acid Cer) in U87-LXSN and U87-W E6 cells. U87-LXSN and U87-W E6 cells were irradiated at $25 \mathrm{~Gy}$, and incubated for the indicated periods. Cellular proteins were subjected to SDS-PAGE and immunoblotted with antibodies against acid ceramidase or actin (reference control). Results are representative of three separate experiments with compatible outcomes

the number of apoptotic cells were almost doubled. Even in U87-LXSN and U87-M E6, cells resistant to $\gamma$-radiation, radiation-induced $\left[{ }^{14} \mathrm{C}\right]$ ceramide formation became evident (a 4.5-fold increase over the control level) when their acid ceramidases were downregulated by exposure to $25 \mu \mathrm{M} \mathrm{OE}$. These radiation-resistant cells were then sensitized by $O E$ to radiation-induced apoptosis. The number of apoptotic cells increased 5.5-fold over the control level on day 3 after $\gamma$ radiation. Therefore, downregulation of a $c$ eramide-degrading enzyme leads to amplify ceramide accumulation and then sensitize cells to radiation-induced apoptosis. 
a

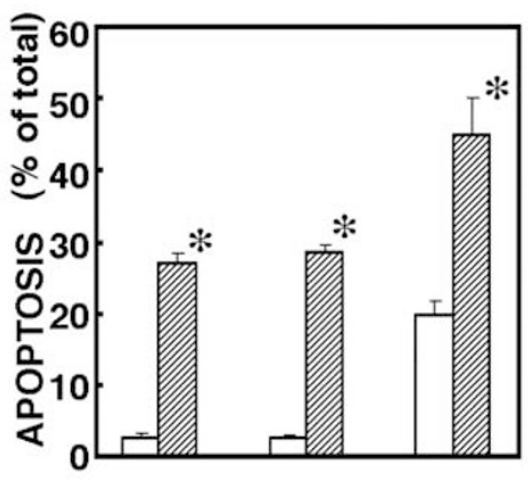

b

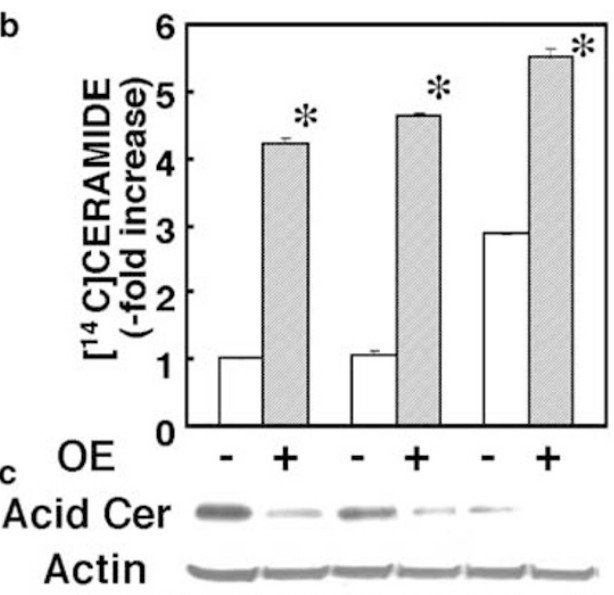

U87-LXSN U87-ME6 U87-WE6

Figure 8 Effects of $\mathrm{OE}$ on radiation-induced apoptosis and ceramide formation. U87-LXSN, U87-M E6, and U87-W E6 cells were preincubated without or with $25 \mu \mathrm{M} \mathrm{OE}$ for $24 \mathrm{~h}$, and then were irradiated at $25 \mathrm{~Gy}$. (a) The cells with fragmented and condensed nuclei, stained with Hoechst 33258, were counted in over 1000 cells under a fluorescent microscope 3 days after $\gamma$ radiation. (b) Formation of $\left[{ }^{14} \mathrm{C}\right]$ ceramide in $\left[{ }^{14} \mathrm{C}\right]$ palmitic acid-labeled cells was determined at day 3 after $\gamma$-radiation. The radioactivity in $\left[{ }^{14} \mathrm{C}\right]$ ceramide of U87LXSN without OE was designed as control. Data are means \pm S.D. from three independent experiments. ${ }^{\star} P<0.01$ versus $\gamma$-radiation alone: two-way ANOVA followed by Scheffe's post hoc test. (c) Cellular proteins were subjected to SDSPAGE and immunoblotted with antibodies against acid ceramidase or actin (reference control). Results are representative of three separate experiments with compatible outcomes

\section{Depletion of functional p53 by retroviral expression of shRNA specific for p53 sensitizes human glioma cells to $\gamma$-radiation-induced apoptosis}

Wild-type HPV-16 E6 protein, but not mutant E6 protein, sensitized radiation-resistant U87-MG cells with wild-type p53, suggesting a role for p53 in radiation resistance. However, like p53, HPV-16 E6 protein modulates a variety of proteins involved in important cellular functions. ${ }^{27-31}$ As another approach to silencing p53, we employed a siRNA technique $^{21}$ that uses retroviral delivery of shRNA. The $\gamma$ radiation-induced accumulation of p53 and p53-dependent proteins, such as $\mathrm{p} 21^{\mathrm{WAF} 1}$ and GADD45, was abrogated in U87-MG cells infected with retrovirus expressing p53 shRNA (designated U87-p53SI) compared to backbone vector (U87Vec) (Figure 9a and b). Therefore, p53 was successfully knocked down by this technique. As was the case when

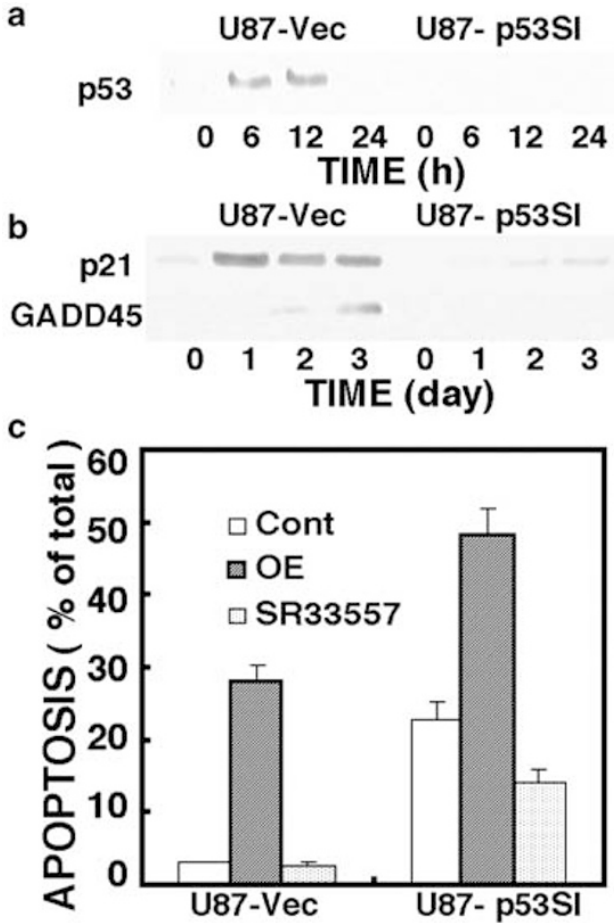

Figure 9 Sensitization to $\gamma$-radiation in cells depleted of functional p53 by retroviral expression of shRNA. U-87 MG cells transduced with SI-MSCVpuroH1R-p53Ri (designed as U87-p53SI) and SI-MSCVpuro-H1R (U87-Vec) were irradiated at $25 \mathrm{~Gy}$, and incubated for the indicated periods. (a and b) Cellular proteins were subjected to SDS-PAGE and immunoblotted with antibodies against p53, p21 $1^{\mathrm{WAF} 1}$, and GADD45. Data are representative of three separate experiments with compatible outcomes. (c) The cells preincubated with $5 \mu \mathrm{M}$ SR33557 for $6 \mathrm{~h}$ or with $25 \mu \mathrm{M}$ OE for $24 \mathrm{~h}$ were irradiated at $25 \mathrm{~Gy}$, and incubated for 3 days. The cells with fragmented and condensed nuclei were counted in over 1000 cells under a fluorescent microscope. Data are means \pm S.D. from three independent experiments, each performed in duplicate

functional p53 was disrupted by HPV-16 E6 retroviral infection, U87-Vec and U87-p53SI cells differed in their radiosensitivity: U87-p53SI cells lacking p53 became sensitive to $\gamma$-radiation, while U87-Vec cells that possessed wildtype p53 were radiation resistant (Figure 9c). SR33557, an inhibitor of A-SMase, suppressed $\gamma$-radiation-induced apoptosis of U87-p53SI cells. In contrast, OE accelerated the radiation-induced death of U87-p53SI and U87-Vec cells. These results confirm the role of ceramide formed by A-SMase during $\gamma$-radiation-induced apoptosis.

\section{Discussion}

Wild-type p53 protein can transcriptionally activate genes involved in cell-cycle arrest, DNA repair and synthesis, or apoptosis. ${ }^{10}$ In a normal cell, p53-dependent cell-cycle arrest allows enough time for DNA damaged by agents to be repaired. If the damage is beyond repair, p53-dependent apoptosis occurs to prevent transfer of new mutations to daughter cells. ${ }^{9}$ Thus, wild-type p53 has been shown to suppress cell transformation and to induce apoptosis in several types of tumors. Adenovirus-mediated delivery of p53 gene caused apoptosis in glioma cell lines containing mutant p53 gene. ${ }^{14}$ However, in response to exogenous 
delivery of supraphysiological levels of p53, glioma cells with wild-type p53 did not undergo apoptosis, ${ }^{14}$ but showed a slower growth rate and became sensitive to radiation-induced apoptosis. ${ }^{15-17}$ These results indicate that the function of p53 is under strict control, which depends on cellular conditions, and that p53 alone, even at supraphysiological levels, cannot trigger apoptotic signaling pathway.

In the present study, we first attempted to investigate the involvement of endogenous p53 in the radiation sensitivity of glioma cells. We found U-373 MG human glioma cells possessing mutant (nonfunctional) p53 to be more sensitive to $\gamma$-irradiation than U-87 MG human glioma cells with wildtype (functional) p53. To confirm these observations, we generated U87-W E6 cells depleted of p53 by HPV-16 E6 protein, ${ }^{20}$ as an isogenic clonal derivative of $U-87$ MG cells. In response to $\gamma$-radiation, accumulation of p53 protein and p53inducible proteins ${ }^{10}$ such as $\mathrm{p} 21^{\mathrm{WAF} 1}$ and GADD45 was observed in vector-infected U87-LXSN cells and U87-M E6 cells infected with mutant E6 proteins. $^{21}$ In contrast, $\gamma$ radiation-induced expression of p53 itself and p53-inducible proteins was abolished in U87-W E6 cells. Therefore, endogenous p53 was successfully eliminated by HPV-16 E6 protein in U87-W E6 cells. Typical apoptotic changes, including nuclear morphological changes and activation of caspases at $96 \mathrm{~h}$ (4 days) after $\gamma$-irradiation, were observed in U87-W E6 cells, but scarcely in U87-LXSN and U87-M E6 cells. The difference in radiation sensitivity between glioma cells with and without endogenous functional p53 was confirmed by clonogenic assay for survival. Since recent studies $^{27-31}$ have identified a number of additional cellular targets of HPV-16 E6 protein, we also downregulated p53 by means of siRNA. U87-p53SI cells in which p53 was effectively knocked down, became susceptible to $\gamma$-radiation-induced apoptosis. These results suggest that glioma cells without functional p53 are more sensitive to $\gamma$-radiation than those with wild-type p53, and are consistent with the results reported by Haas-Kogan et al., ${ }^{18}$ who proposed that endogenous functional p53 mediated radiation-induced $G_{1}$ arrest rather than apoptosis. It may be reasonable to speculate that p53dependent induction of p21 WAF1 observed in Figure 2 takes part in radiation-induced $\mathrm{G}_{1}$ arrest. Our present observations are, however, inconsistent with the report by Badie et al., ${ }^{16}$ that radiation induces significant apoptosis neither in U-373 MG cells with mutant p53 nor in U-87 MG cells possessing functional p53. This discrepancy may be due to differences in the time that elapsed between the $\gamma$-radiation and examination, the $\gamma$-radiation doses, or the method used to detect apoptosis. They measured apoptosis only $48 \mathrm{~h}$ after $\gamma$ radiation, whereas we measured it for 4 days and HaasKogan et al. measured it for 8 days, ${ }^{18}$ and they did not observe kinetic changes. In addition, their radiation dose was lower than that of ours. In our kinetic analysis (Figure 1a), at $48 \mathrm{~h}$ (2 days) after $\gamma$-irradiation, the number of apoptotic U87-W E6 cells was less than $10 \%$, but it reached nearly $40 \%$ at 4 days. Therefore, we believe that they would have been able to detect differences between U-373 MG cells and U-87 MG cells after longer incubation periods. Taken together, our results indicate that p53-independent apoptotic signaling pathways operate in $\gamma$-irradiated glioma cells, and that endogenous functional p53 may counteract these signals. We next examined the involvement of ceramide in p53-independent apoptotic pathway. Ceramide has been shown to exert potent proapoptotic effects in a variety of cell types. ${ }^{5}$ Ceramide is mainly produced from SM by the action of $\mathrm{N}$ SMase and/or A-SMase during apoptosis. N-SMase has been implicated in apoptosis induced by serum starvation, ${ }^{32}$ hypoxia, ${ }^{33}$ nitric oxide, ${ }^{34}$ and some chemotherapeutic agents. $^{6,35}$ In glioma cells treated with etoposide, activation of N-SMase occurred downstream of p53-mediated ROS formation. ${ }^{8}$ In contrast, A-SMase has been suggested to be activated in cells exposed to radiation, ${ }^{36} \mathrm{Fas},{ }^{24,37}$ and TNF$\alpha^{38}$ In $\gamma$-irradiated U87-W E6 cells, ceramide was produced with increased A-SMase activity, but not increased N-SMase activity. However, significant ceramide formation and activation of A-SMase were not observed in radioresistant U87LXSN cells expressing functional p53. Inhibition of $\gamma$-radiationinduced ceramide formation by an inhibitor of A-SMase, $\mathrm{SR} 33557,{ }^{23,24}$ resulted in the suppression of apoptosis. In contrast, enhancement of ceramide formation by OE potentiated radiation-induced apoptotic cell death. These results indicate that ceramide produced by A-SMase activation plays a pivotal role during p53-independent radiation-induced glioma cell apoptosis. Recent studies ${ }^{36,39-41}$ have implicated ceramide in radiation sensitivity. The production of ceramide was deficient in the radioresistant lymphoid cell line WEHI-231 OE, although wild-type WEHI-231 JM cells accumulated ceramide in response to $\mathrm{X}$-irradiation and underwent apoptosis. $^{39}$ The necessity of A-SMase (ceramide producing enzyme) in radiation-induced ceramide formation has also been demonstrated in cells from A-SMase-deficient Niemann-Pick patients and from A-SMase-knockout mice. ${ }^{36}$ In highly radiation-resistant $\mathrm{LNCaP}$ prostate cancer cells, $\gamma$ irradiation had no effect on ceramide production. ${ }^{41}$ However, these cells can be sensitized to radiation-induced cell death by exogenous $\mathrm{C}_{2}$-ceramide or TNF- $\alpha$, which increases ceramide formation. The effects of ceramide are thought to be mediated by serine proteases, which trigger mitochondrial membrane depolarization and caspase- 9 activation. These and our present results suggest that suppressed activation of A-SMase (ceramide-producing enzyme) and upregulation of acid ceramidase (ceramide-degrading enzyme), both of which inhibit ceramide accumulation, are involved in radioresistance of glioma cells with endogenous functional p53. Significant radiation-induced activation of $A$-SMase was observed in neither U87-LXSN nor U87-M E6 cells expressing functional p53. Although no upstream regulator of A-SMase has been identified yet, our results implicate p53 in the blockage of ASMase. The substances involved in and the processes of radiation-induced activation of A-SMase will be the subject of future investigation. To our knowledge, we have, for the first time, demonstrated upregulation of acid ceramidase in response to $\gamma$-radiation. Its increase was more prominent in glioma cells possessing endogenous functional p53 than in cells depleted of p53 by HPV-16 E6 protein. Therefore, p53 may play a role in the expression of acid ceramidase. OE, which is often used to inhibit ceramidase activity, ${ }^{6,25,26}$ unexpectedly, downregulated radiation-induced expression of acid ceramidase. This drug accelerated radiation-induced apoptosis of U87-W E6 cells through enhanced accumulation of ceramide. Moreover, radioresistant U87-LXSN and U87-M 
E6 cells can be sensitized to radiation-induced cell death by OE. Ceramide degradation is the only catabolic source of intracellular sphingosine. ${ }^{42}$ Acid ceramidase activity may be the rate-limiting step in determining the intracellular levels of sphingosine, and subsequently, sphingosine-1-phosphate (SPP), an inducer of proliferation and survival. ${ }^{43,44}$ Therefore, ceramidase plays a crucial role in the determination of ceramide/SPP ratio and, consequently, in cell survival or cell death in response to external stimuli.

In summary, ceramide generated through the activation of A-SMase, but not $\mathrm{N}$-SMase, triggers $\gamma$-radiation-induced apoptosis in human glioma cells without functional p53, and that endogenous wild-type p53 eliminates the ceramide signal through upregulating acid ceramidase and blockade of ASMase, and then protects glioma cells from $\gamma$-radiationinduced apoptosis. Further studies are necessary to clarify the relationship between p53 status and radiation sensitivity. Elucidation of the roles of p53 in ceramide metabolism (both production and elimination) may provide an insight into the development of $\gamma$-radiation therapy for malignant brain tumor.

\section{Materials and Methods}

\section{Reagents}

Dulbecco's modified Eagle's medium (DMEM) was purchased from Nipro (Osaka, Japan). Penicillin/ streptomycin was from Gibco-BRL (Grand Island, NY, USA). Fetal bovine serum (FBS) was from Irvine Scientific (Santa Ana, CA, USA). Gateway adaptor PCR system, pDONR221, BP clonase, and LR clonase were from Invitrogen (Tokyo, Japan). MTT, OE, and $E$. coli diacylglycerol kinase were obtained from Sigma (St. Louis, MO, USA). Immobilon-P membranes were from Millipore (Bedford, MA, USA). A protease inhibitor E-64 was obtained from Peptide Institute (Osaka, Japan). $\left[\gamma_{-}{ }^{32} \mathrm{P}\right] \mathrm{ATP}$ and ECL Western blotting detection reagents were from Amersham (Buckinghamshire, UK). $\left[1-{ }^{14} \mathrm{C}\right] \mathrm{Palmitic}$ acid $(55.0 \mathrm{mCi} /$ mmol) was from ICN (Irvine, CA, USA). [choline-methyl- ${ }^{14} \mathrm{C}$ ]SM $(52.0 \mathrm{mCi} /$ mmol) was from NEC Life Science Products (Boston, MA, USA). Highperformance thin-layer chromatography (HPTLC) plates were from Merck (Darmstadt, Germany). SR33557 was kindly supplied by Dr. Jean-Marc Herbert (Sanofi-Synthelabo Recherche, France). The primary antibodies used were anti-p53 monoclonal antibody (Ab-6) (Calbiochem-Novabioochem International, Boston, MA, USA), anti-acid ceramidase monoclonal antibody (Transduction Laboratories, Lexington, KY, USA), anti-p21 WAF1 polyclonal antibody (Santa Cruz Biotechnology, CA, USA), anti-GADD45 polyclonal antibody (Santa Cruz Biotechnology), and anti-actin monoclonal antibody (Calbiochem-Novabiochem International). BCA protein assay reagents were obtained from Pierce (Rockford, IL, USA). Other chemicals were of the highest quality available.

\section{Cell culture and stimulation}

The human U-87 MG glioblastoma cell lines were obtained from American Type Culture Collection (Rockville, MD, USA). U87-LXSN, U87-W E6, and U87-M E6 cell lines were obtained by infecting U-87 MG cells with LXSN, LXSN-16E6SD, and LXSN-16E6SD-8S9A10 T retroviruses, respectively, followed by drug selection with $800 \mu \mathrm{g} / \mathrm{ml} \mathrm{G} 418$ for 2 weeks. ${ }^{8}$ p53 was also targeted by siRNA using retroviral delivery of shRNA. To generate retrovirus vector expressing shRNA, the self-inactivating virus vector was used. The $3^{\prime}$-LTR in a murine stem cell virus vector, pCMSCVpuroDEST, ${ }^{45}$ was inactivated by an internal deletion (Nhel-Xbal). The self- inactivating virus vector was named pSI-CMSCVpuro-DEST. The H1 promoter cassette with or without stuffer previously described by Brummelkamp et al. ${ }^{21}$ was attached by attB2 and attB1 sequences by adaptor PCR, and recombined into pDONR221 by BP reaction according to the manufacturer's instruction to generate pENTR221-H1R-stuffer or pENTR-H1R. To generate pENTR221-H1Rp53Ri, the pENTR221-H1Rstuffer was digested with Bgll and Hindll, and the annealed oligos (5'gatccccGACTCCAGTGGTAATCTACttcaagagaGTAGATTGAGTCtttttCtttttggaaa3' and 5'agctttccaaaaaGACTCCAGTGGTAATCTACtctcACtctcttgaaGTAGCTGGAGTCggg $\left.3^{\prime}\right)^{21}$ were replaced with the stuffer. Both the inserts were recombined into pSI-CMSCVpuro-DEST by LR reaction according to the manufacturer's instruction to generate pSICMSCVpuro-H1R-p53Ri and pSI-CMSCVpuro-H1R. U-87 MG cells expressing p53 shRNA (designed as U87-p53SI) and the control cells H1R (U87-Vec) were obtained by infection of SI-MSCVpuro-H1R-p53Ri and the backbone (SI-MSCVpuro-H1R) retroviruses, respectively, followed by selection with $1 \mu \mathrm{g} / \mathrm{ml}$ of puromycin. The cells were maintained in DMEM supplemented with $10 \%(\mathrm{v} / \mathrm{v}) \mathrm{FBS}, 100 \mathrm{U} / \mathrm{ml}$ penicillin, and $100 \mu \mathrm{g} / \mathrm{ml}$ streptomycin (FBS/DMEM) in a humidified atmosphere containing $5 \% \mathrm{CO}_{2}$ at $37^{\circ} \mathrm{C}$. Prior to $\gamma$-radiation, the cells were plated at a density of $1 \times 10^{4} / \mathrm{ml}$ and cultured for 3 days. Cells were irradiated using a ${ }^{137}$ Cs source (IBL 437C Irradiator, CIS bio international, Gif-sur-Yvette, France) at a dose rate of $6.0 \mathrm{~Gy} / \mathrm{min}$.

\section{Determination of apoptosis}

Apoptotic cells stained with Hoechst 33258 were quantified by fluorescent microscopic analysis. ${ }^{33}$ Briefly, cells were fixed in $1 \%$ glutaraldehyde for $30 \mathrm{~min}$. The cells were then stained with $10 \mu \mathrm{M}$ Hoechst 33258 for $10 \mathrm{~min}$. Nuclear morphology was observed under a fluorescent microscope (Olympus BX60, Tokyo, Japan). For MTT assay, 500 cells were plated in 96-well microplates in $100 \mu \mathrm{l}$ FBS/DMEM and cultured for 2 days prior to irradiation. At 3 days after $\gamma$-radiation, $50 \mu \mathrm{l}$ MTT reagent $(5 \mathrm{mg} / \mathrm{ml}$ in phosphate-buffered saline, PBS) was added to each well. After incubation at $37^{\circ} \mathrm{C}$ for $2 \mathrm{~h}$, MTT was removed from the well, and the MTT formazon product was dissolved in $100 \mu \mathrm{l}$ of dimethyl sulfoxide. The absorbance of the sample at $560 \mathrm{~nm}$ was measured using a microplate reader (Immuno Mini NJ2300, System Instruments, Tokyo, Japan).

\section{Colony formation assay}

U87-LXSN, U87-M E6, and U87-W E6 cells were irradiated at various doses, and cultured for 3 days. The cells treated with $\gamma$-radiation were washed with PBS and trypsinized. All the groups were replated at a density of 3000 cells $/ 100 \mathrm{~mm}$ Petri dish in triplicate, and incubated for 2 weeks to allow colonies to develop. After 2 weeks, the medium was removed and the colonies were washed once with PBS, and fixed with $75 \%$ methanol in $25 \%$ acetic acid for $5 \mathrm{~min}$ and then the plates were dried. Colonies were stained with trypan blue in $50 \%$ ethanol for $10 \mathrm{~min}$ and subsequently washed with deionized water to remove excess dye.

\section{SMase assay}

Membrane fraction was prepared as described previously. ${ }^{6,24 .}$ The activities of both $\mathrm{N}$ - and A-SMases were determined using a mixed micelle assay system. ${ }^{6-8}$ For measuring N-SMase activity, the membrane fractions (20 $\mu \mathrm{g}$ protein) were mixed with [choline-methyl $\left.{ }^{14} \mathrm{C}\right] \mathrm{SM}$ (40000 c.p.m. in $1 \mathrm{nmol}$ of bovine brain SM in $0.25 \%$ Triton X-100 solubilized by sonication) in $0.1 \mathrm{M}$ Tris/ $\mathrm{HCl}$ buffer $(\mathrm{pH} 7.4)$ containing $6 \mathrm{mM} \mathrm{MgCl}_{2}$, and the reaction mixture was incubated for $30 \mathrm{~min}$ at $37^{\circ} \mathrm{C}$. 
A-SMase activity in the membrane was measured as above, except that the Tris/ $\mathrm{HCl}$ buffer was replaced with $0.1 \mathrm{M}$ sodium acetate buffer $(\mathrm{pH} 5.5)$ containing $5 \mathrm{mM}$ EDTA.

\section{Measurement of cellular ceramide}

Lipids extracted from cells were first treated in $0.1 \mathrm{M} \mathrm{KOH}$ in chloroform: methanol $(1: 2, \mathrm{v} / \mathrm{v})$ at $37^{\circ} \mathrm{C}$ for $1 \mathrm{~h} .^{6,33}$ Ceramide was converted to ceramide $\left.1-{ }^{32} \mathrm{P}\right]$ phosphate by $E$. coli diacylglycerol kinase in the presence of $\left[\gamma_{-}{ }^{32} \mathrm{P}\right] A T P,{ }^{6,33}$ and then lipids were separated on HPTLC plates in a solvent system of chloroform:acetone: methanol:acetic acid: water $(50: 20: 15: 10: 5, \mathrm{v} / \mathrm{v})$. Following autoradiography, spots corresponding to ceramide 1-phosphate were scraped into vials and the radioactivity was counted in a scintillation counter (Beckman LS-6500). Quantitation of ceramide was based on a standard curve of known amounts of ceramide. The changes in ceramide content were normalized based on total protein. The changes of cellular ceramide levels were also analyzed in cells labeled with $\left[{ }^{14} \mathrm{C}\right]$ palmitic acid. ${ }^{6,33}$ To radiolabel sphingolipids, cells were labeled with $\left[{ }^{14} \mathrm{C}\right]$ palmitic acid $(1 \mu \mathrm{Ci} / \mathrm{ml})$ for $24 \mathrm{~h}$. The changes in $\left[{ }^{14} \mathrm{C}\right]$ ceramide were normalized based on $100 \mu \mathrm{g}$ of protein.

\section{Western blot analysis}

Cells were solubilized with ice-cold lysis buffer containing $1 \%$ Triton X-100, $50 \mathrm{mM} \mathrm{NaCl}, 25 \mathrm{mM}$ HEPES (pH 7.4), $1 \mathrm{mM}$ EDTA, $1 \mathrm{mM}$ phenylmetylsulfonyl fluoride, and $10 \mu \mathrm{g} / \mathrm{ml}$ E-64. Extracted proteins (60 $\mu \mathrm{g} / \mathrm{well})$ were separated by sodium dodecylsulfate polyacrylamide gel electrophoresis (SDS-PAGE) on 6,10 , or $13 \%$ polyacrylamide gels, and were electrophoretically transferred onto Immobilon-P membrane. Blocking was performed in Tris-buffered saline containing 5\% skimmed-milk powder and $0.1 \%$ Tween-20. The membranes were probed with antibodies against acid ceramidase and actin. Detection was performed with ECL system. Protein content was determined with BCA protein assay using bovine serum albumin as a standard.

\section{Statistical analysis}

Data are expressed as means \pm S.D. Significance was assessed by twoway ANOVA, followed by Scheffe's post hoc test. $P$-values less than 0.01 were considered as significant.

\section{Acknowledgements}

We are grateful to Jean-Marc Herbert (Sanofi-Synthelabo Recherche, France) for SR33557. This work was supported in part by Grants-in-Aid for Scientific Research (B) (14370429) and Cancer Research (14026065) from The Ministry of Education, Culture, Sports, Science and Technology of Japan. M Sawada is a Research Fellow of the Japan Society for the Promotion of Science.

\section{References}

1. Sheline GE (1977) Radiation therapy of brain tumors. Cancer 39: 873-881

2. Taghian A, Suit H, Pardo F, Gioioso D, Tomkinson K, DuBois W and Gerweck L (1992) In vitro intrinsic radiation sensitivity of glioblastoma multiforme. Int. J. Radiat. Oncol. Biol. Phys. 23: 55-62

3. Sellers WR and Fisher DE (1999) Apoptosis and cancer drug targeting. J. Clin. Invest. 104: 1655-1661
4. Wolf BB and Green DR (1999) Suicidal tendencies: apoptotic cell death by caspase family proteinases. J. Biol. Chem. 274: 20049-20052

5. Hannun YA (1996) Functions of ceramide coordinating cellular responses to stress. Science 274: 1855-1859

6. Sawada M, Nakashima S, Banno Y, Yamakawa H, Hayashi K, Takenaka K, Nishimura Y, Sakai N and Nozawa Y (2000) Ordering of ceramide formation, caspase activation, and $\mathrm{Bax} / \mathrm{Bcl}-2$ expression during etoposide-induced apoptosis in C6 glioma cells. Cell Death Differ. 7: 761-772

7. Sawada M, Nakashima S, Banno Y, Yamakawa H, Takenaka K, Shinoda J, Nishimura Y, Sakai N and Nozawa Y (2000) Influence of Bax or Bcl-2 overexpression on the ceramide-dependent apoptotic pathway in glioma cells. Oncogene 19: 3508-3520

8. Sawada M, Nakashima S, Kiyono T, Nakagawa M, Yamada J, Yamakawa H, Banno Y, Shinoda J, Nishimura Y, Nozawa Y and Sakai N (2001) p53 regulates ceramide formation by neutral sphingomyelinase through reactive oxygen species in human glioma cells. Oncogene 20: 1368-1378

9. Waldman T, Zhang Y, Dillehay L, Yu J, Kinzler K, Vogelstein B and Williams J (1997) Cell-cycle arrest versus cell death in cancer therapy. Nat. Med. 3: 10341036

10. El-Deiry WS (1998) Regulation of p53 downstream genes. Semin. Cancer Biol. 8: $345-357$

11. Moroni MC, Hickman ES, Denchi EL, Caprara G, Colli E, Cecconi F, Muller H and Helin K (2001) Apaf-1 is a transcriptional target for E2F and p53. Nat. Cell Biol. 3: 552-558

12. Dbaibo GS, Pushkareva MY, Rachid RA, Alter N, Smyth MJ, Obeid LM and Hannun YA (1998) p53-dependent ceramide response to genotoxic stress. J. Clin. Invest. 102: 329-339

13. Tepper AD, de Vries E, van Blitterswijk WJ and Borst J (1999) Ordering of ceramide formation, caspase activation, and mitochondrial changes during CD95- and DNA damage-induced apoptosis. J. Clin. Invest. 103: 971-978

14. Gomez-Manzano C, Fueyo J, Kyritsis AP, Steck PA, Roth JA, McDonnell TJ, Steck KD, Levine VA and Youg WKA (1996) Adenovirus-mediated transfer of the $p 53$ gene produces rapid and generalized death of human glioma cells via apoptosis. Cancer Res. 56: 694-699

15. Lang FF, Yung WK, Raju U, Libunao F, Terry NH and Tofilon PJ (1998) Enhancement of radiosensitivity of wild-type p53 human glioma cells by adenovirus-mediated delivery of the p53 gene. J. Neurosurg. 89: 125-132

16. Badie B, Goh CS, Klaver J, Herweijer H and Boothman DA (1999) Combined radiation and p53 gene therapy of malignant glioma cells. Cancer Gene Ther. 6 : 155-162

17. Shono T, Tofilon PJ, Schaefer TS, Parikh D, Liu T-J and Lang FF (2002) Apoptosis induced by adenovirus-mediated p53 gene transfer in human glioma correlates with site-specific phosphorylation. Cancer Res. 62: 1069-1076

18. Haas-Kogan DA, Yount G, Haas M, Levi D, Kogan SS, Hu L, Vidair C, Deen DF, Dewey WC and Israel MA (1996) p53-dependent G1 arrest and p53independent apoptosis influence the radiobiologic response of glioblastoma. Int. J. Radiat. Oncol. Biol. Phys. 36: 95-103

19. Tada M, Matsumoto R, Iggo RD, Onimaru $R$, Shirato $H$, Sawamura $Y$ and Shinohe $Y(1998)$ Selective sensitivity to radiation of cerebral glioblastomas harboring p53 mutations. Cancer Res. 58: 1793-1797

20. Scheffner M, Huibregtse JM, Vierstra RD and Howley PM (1993) The HPV-16 E6 and E6-AP complex functions as a ubiquitin-protein ligase in the ubiquitination of p53. Cell 75: 495-505

21. Brummelkamp TR, Bernards $R$ and Agami $R$ (2002) A system for stable expression of short interfering RNAs in mammalian cells. Science 296: 550553

22. Kiyono T, Foster SA, Koop JI, McDougall JK, Galloway DA and Klingelhutz AJ (1998) Both $\mathrm{Rb} / \mathrm{p} 16^{\mathrm{INK} 4 \mathrm{a}}$ inactivation and telomerase activity are required to immortalize human epithelial cells. Nature 396: 84-88

23. Jaffrezou JP, Levada T, Chatelain P and Laurent G (1992) Modulation of subcellular distribution of doxorubicin in multidrug resistant P388/ADR mouse leukemia cells by the chemosensitizer (2-isopropyl-1-(4-[3- $\mathrm{N}$-methyl- $\mathrm{N}$-(3,4dimethoxy- $\beta$-phenethyl)amino]propyloxy)-benzenesulfonyl)indolizine. Cancer Res. 52: 6440-6446

24. Sawada M, Nakashima S, Kiyono T, Yamada J, Hara S, Nakagawa M, Shinoda $J$ and Sakai N (2002) Acid sphingomyelinase activation requires caspase-8 but not $p 53$ nor reactive oxygen species during Fas-induced apoptosis in human glioma cells. Exp. Cell Res. 273: 157-168 
25. Strelow A, Bernardo K, Adam-Klages S, Linke T, Sandhoff K, Kronke M and Adam D (2000) Overexpression of acid ceramidase protects from tumor necrosis factor-induced cell death. J. Exp. Med. 192: 601-612

26. Harel R and Futerman AH (1993) Inhibition of sphingolipid synthesis affects axonal outgrowth in cultured hippocampal neurons. J. Biol. Chem. 268: 1447614481

27. Chen JJ, Reid CE, Band V and Androphy EJ (1995) Interaction of papillomavirus E6 oncoproteins with a putative calcium-binding protein. Science 269: 529-531

28. Tong $X$ and Howley PM (1997) The bovine papillomavirus E6 oncoprotein interacts with paxillin and disrupts the actin cytoskeleton. Proc. Natl. Acad. Sci. USA 94: 4412-4417

29. Gao Q, Srinivasan S, Boyer S, Wazer D and Band V (1999) The E6 oncoproteins of high-risk papillomaviruses bind to a novel putative GAP protein, E6TP1, and target it for degradation. Mol. Cell. Biol. 19: 733-744

30. Zimmermann H, Degenkolbe R, Bernard HU and O'Connor MJ (1999) The human papillomavirus type $16 \mathrm{E} 6$ oncoprotein can down-regulate p53 activity by targeting the transcriptional coactivator CBP/p300. J. Viol. 73: 6209-6219

31. Gao Q, Kumar A, Srinivasan S, Singh L, Mukai H, Ono Y, Wazer DE and Band $V(2000) P K N$ binds and phosphorylates human papillomavirus E6 oncoprotein. J. Biol. Chem. 275: 14824-14830

32. Jayadev S, Liu B, Bielawska A, Lee J, Nazaire F, Pushkareva MY, Obeid L and Hannun YA (1995) Role for ceramide in cell cycle arrest. J. Biol. Chem. 270 2047-2052

33. Yoshimura S, Banno Y, Nakashima S, Takenaka K, Sakai H, Nishimura $Y$ Sakai N, Shimizu S, Eguchi Y, Tsujimoto Y and Nozawa Y (1998) Ceramide formation leads to caspase-3 activation during hypoxic $\mathrm{PC} 12$ cell death. J. Biol. Chem. 273: 6921-6927

34. Takeda Y, Tashima M, Takahashi A, Uchiyama T and Okazaki T (1999) Ceramide generation in nitric oxide-induced apoptosis. Activation of magnesium-dependent neutral sphingomyelinase via caspase-3. J. Biol. Chem. 274: 10654-10660

35. Jaffrezou JP, Levade T, Bettaieb A, Andrieu N, Bezombes C, Maestre N, Vermeersch S, Rousse A and Laurent G (1996) Daunorubicin-induced apoptosis: triggering of ceramide generation through sphingomyelin hydrolysis. EMBO J. 15: 2417-2424
36. Santana P, Pena LA, Haimovitz-Friedman A, Martin S, Green D, McLoughlin M, Cordon-Cardo C, Schuchman EH, Fuks Z and Kolesnick R (1996) Acid sphingomyelinase-deficient human lymphoblasts and mice are defective in radiation-induced apoptosis. Cell 86: 189-199

37. Cifone MG, De Maria R, Roncaioli P, Rippo MR, Azuma M, Lanier LL, Santoni A and Testi R (1994) Apoptotic signaling through CD95 (Fas/Apo-1) activates an acidic sphingomyelinase. J. Exp. Med. 180: 1547-1552

38. Schwandner R, Wiegmann K, Bernardo K, Kreder D and Kronke M (1998) TNF receptor death domain-associated proteins TRADD and FADD signal activation of acid sphingomyelinase. J. Biol. Chem. 273: 5916-5922

39. Chmura SJ, Nodzenski E, Beckett MA, Kufe DW, Quintans J and Weichselbaum RR (1997) Loss of ceramide production confers resistance to radiation-induced apoptosis. Cancer Res. 57: 1270-1275

40. Alphonse G, Aloy MT, Broquet P, Gerard JP, Louisot P, Rousson R and Rodriguez-Lafrasse C (2002) Ceramide induces activation of the mitochondrial/ caspases pathway in Jurkat and SCC61 cells sensitive to $\gamma$-radiation but activation of this sequence is defective in radioresistant SQ20B cells. Int. J. Radiat. Biol. 78: 821-835

41. Kimura K, Markowski M, Edsall LC, Spiegel S and Gelmann EP (2003) Role of ceramide in mediating apoptosis of irradiated $\mathrm{LNCaP}$ prostate cancer cells. Cell Death Differ. 10: 240-248

42. Cuvillier O, Pirianov G, Kleuser B, Vanek PG, Coso OA, Gutkind S and Spiegel $S$ (1996) Suppression of ceramide-mediated programmed cell death by sphingosine-1-phosphate. Nature 381: 800-803

43. An S, Zheng Y and Bleu T (2000) Sphingosine 1-phosphate-induced cell proliferation, survival, and related signaling events mediated by $G$ proteincoupled receptors Edg3 and Edg5. J. Biol. Chem. 275: 288-296

44. Osawa Y, Banno Y, Nagaki M, Brenner DA, Naiki T, Nozawa Y, Nakashima S and Moriwaki H (2001) TNF- $\alpha$-induced sphingosine 1-phosphate inhibits apoptosis through a phosphatidylinositol 3-kinase/Akt pathway in human hepatocytes. J. Immunol. 167: 173-180

45. Takeda Y, Mori T, Imabayashi H, Kiyono T, Gojo S, Miyoshi S, Ita M, Segawa K, Ogawa S, Sakamoto M, Nakamura S and Umezawa A (2004) Can the lifespan of human marrow stromal cells be prolonged by bim-1, E6, E7, and/or telomerase without affecting cardiomyogenic differentiation? J. Gene Med., (in press). 